\title{
A Dialkyldithiophosphate Derivative as Mild Steel Corrosion Inhibitor in Sulfuric Acid Solution
}

\author{
Xiulan Su ${ }^{1}$, Chuan Lai ${ }^{1,2 *}$, Lincai Peng ${ }^{1}$,Hui Zhu ${ }^{1}$, Lvshan Zhou ${ }^{1}$, Lei Zhang, Xingqin Liu, Wei Zhang ${ }^{1}$ \\ ${ }^{1}$ School of Chemistry and Chemical Engineering, Sichuan University of Arts and Science, Dazhou \\ 635000, PR China \\ ${ }^{2}$ Material Corrosion and Protection Key Laboratory of Sichuan Province, Sichuan University of \\ Science and Engineering, Zigong 643000, PR China \\ *E-mail: laichuanemail@163.com
}

doi: $10.20964 / 2016.06 .45$

Received: 17 March 2016 / Accepted: 8 April 2016 / Published: 4 May 2016

In the present work, N,N-Diethylammonium O,O'-di(4-chlorophenyl)dithiophosphate (Cl-EPP) acting as a mild steel corrosion inhibitor was synthesized. Potentiodynamic polarization measurements, weight loss measurements and scanning electron microscopy were used to evaluate the corrosion inhibition of Cl-EPP for mild steel in sulfuric acid. The results of electrochemical measurements indicate that the Cl-EPP is a mixed type inhibitor. Meanwhile, the inhibition efficiency increase with the increasing of concentration of inhibitor concentration, decrease with the increasing of temperature, sulfuric acid concentration and storage time. In addition, the adsorption of Cl-EPP on mild steel surface is chemical adsorption, and obeys Langmuir isotherm.

Keywords: Corrosion inhibitor; Mild steel; Sulfuric acid; O,O'-dialkyldithiophosphate.

\section{FULL TEXT}

(C) 2016 The Authors. Published by ESG (www.electrochemsci.org). This article is an open access article distributed under the terms and conditions of the Creative Commons Attribution license (http://creativecommons.org/licenses/by/4.0/). 